RAPHISA.

Revista de Antropología y Filosofía de lo Sagrado Review of Anthropology and Philosophy of the Sacrum

ISSN: 2530-1233 N 2,diciembre (2017) pp.: 119-127

\title{
RĀBI'AAL'ADAWIYYAYLAKAABA
}

\section{RĀBI'AAL‘ADAWIYYAAND THEKA'BAH}

\section{Ana Salto Sánchez del Corral ${ }^{1}$ \\ Universidad de Málaga (AEHM) y Consejería de Educación, Junta de Andalucía}

\begin{abstract}
Resumen Este texto se centra en la concepción de la Kaaba de una mujer excepcional por su relación con Dios y por su conocimiento místico (ma'arifa), Rābia al-'Adawiyya (m. 801). Ella protagonizó el paso de la ascética a la mística en la Basora del siglo VIII y marcó una diferencia respecto a los ascetas de su tiempo: realizó el viaje al interior de sí misma y ejerció una continua introspección para buscar el profundo deseo del corazón y purificarlo. Los relatos de la peregrinación a la Kaaba, la Casa o morada de Dios, se comparan a los grados de oración descritos por Teresa de Jesús en el Libro de la Vida.
\end{abstract}

Palabras clave: Kaaba, mística, Rābi'a al-'Adawiyya, Teresa de Jesús

Abstract: This paper focuses on the understanding of the Kaaba by Rābi'a al-'Adawiyya (d: 801), Rābi'a was an exceptional woman due to her relationship with God and her mystical knowledge (ma'arifa). She leaded the passage from asceticism to mysticism in the Basra of 8th century, making a difference with the ascetic of her time: she made a journey to the interior of herself, practicing a continuous introspection in order to pursue the deepest desire of her heart, and to purify it. The accounts of her pilgrimage to the Kaaba - the House or the Dwelling of God - are compared with the degrees of prayer described by Saint Teresa of Ávila in the Libro de la Vida.

Key Words: Kaaba, mysticism, Rābía al-Adawiyya, Saint Teresa of Ávila

[1] (ana.salto.edu@juntadeandalucia.es) Doctora por la universidad de Málaga en el Programa Estudios de mujeres y de género; licenciada en Filología (arabo-islámica) por la Universidad de Granada y en Ciencias Religiosas por la Universidad Pontificia de Comillas, miembro de la Asociación de Estudios Históricos sobre la Mujer (AEHM/UMA) y profesora de Religión y Moral de la Junta de Andalucía. Ha realizado estancias en universidades de Túnez, Damasco, Beirut (USJ) y Filadelfia (UPENN). Ha sido becaria MAE-AECI y ha recibido premios de investigación educativa (“Antonio Domínguez Ortiz XXII Edición” y Galardón Málaga, Excelencia educativa 2010) y de ensayo (XVI Premio Nacional de Ensayo 2015 "Carmen de Burgos"). Ha participado en diversas obras colectivas y es autora de La dignidad humana: dignidad de la mujer, Madrid, PPC, 2007; y de dos libros electrónicos publicados en USA: En Plan de Igualdad. Propuestas Estratégicas de Lectura y Comunicación y Hannah Arendt, Simone de Beauvoir y Edith Stein, Miami, El Cid Editor, 2012. 
Existen varios términos para referirse al misticismo islámico. Taṣawwuf - revestirse de lana, ser sufí- alterna con el término țarìqa, la vía, el itinerario, que alude al componente doctrinal del camino ( $s \bar{u} l \bar{u} k)$ que sigue quien recorre progresivamente las diferentes etapas hacia la unión con Dios. La investigadora de la universidad hebrea de Jerusalén, Sara Sviri, muestra - a partir de las fuentes árabes, cuyo texto original reproduce- cómo el término șūfĩ deriva de șüf (lana) (Sviri, 2012, 22; nn. 11, 12 y 15). Aunque la denominación sufí aplicada al sujeto místico en el islam parece producirse a partir de la segunda mitad del siglo IX, la investigadora israelí reconoce que, de hecho, "[the] mysticism in Islam existed before it became known as Sufism» (Sviri, 2012, 33). A mi juicio, el sufismo o mística islámica, inserto en la tradición judeocristiana, tiene su origen en la propia ascética islámica $(z u h d)$. El paso de la ascética a la mística lo protagonizó una mujer de Basora en el siglo VIII, Rābi'a al-'Adawiyya (m. 801). En este artículo nos centraremos en un aspecto de la espiritualidad de Rābi'a al-'Adawiyya, quien ha sido considerada mujer excepcional por su relación con Dios y por su conocimiento místico (ma'arifa) ('Aț̣ār, 1962, 143).

\section{El camino hacia el Otro y la peregrinación a la Kaaba}

Las fuentes transmisoras de los dichos, hechos y poemas de Rābi'a no siguen la secuencia cronológica de su vida espiritual, salvo, grosso modo, la hagiografía literaria de al-'Aț̣ār. El filósofo egipcio 'Abd al-RaḤmān Badawī (1962) explica el progreso espiritual de Rābi'a al-'Adawiyya como un proceso de elevación del sensualismo a la espiritualización. En mi opinión, se trata de un proceso amoroso vital. La evolución de la relación amorosa se experimenta subjetivamente de modo continuo, si bien, hay vivencias que marcan un hito en su desarrollo.

A tenor de los textos biográficos, Rābi'a al-'Adawiyya siempre mantuvo un espíritu de humilde ascetismo. Ella marcó una diferencia respecto a los ascetas de su tiempo, ufanos de sus prácticas: realizó el viaje al interior de sí misma, ejerció una continua introspección para buscar el profundo deseo del corazón y purificarlo, para procurar la recta intención. En este sentido, afirmaba que lo que sus prácticas tenían de exterioridad y apariencia no tenía ningún valor para ella (Bahā’ al-Dīn, 1962, 165).

Aunque Badawī valora la humildad de Rābi‘a — virtud en la que superó a al-Hallāŷ (m. 922) -, discreparía del filósofo egipcio cuando considera que, en el esfuerzo ascético ( $a l-\hat{y} i h \bar{a} d a l$-nafsī), descansa el único significado de su vida espiritual (Badawī, 1962, 27). Rābi‘a nunca cuenta como mérito ante Dios ninguna de las prácticas de las que alardeaban los 
ascetas de su tiempo. Su única preocupación era si la ofrenda de su cuerpo y su corazón era grata a Dios. Rābi'a expresa la necesidad del ser humano de ser afirmado desde el exterior, la necesidad de un cariño y una acogida desde fuera. La caída de Rābi'a que relata al-'Aț̣ār $r^{2}$ no tiene el mismo significado que la caída del caballo de Pablo, en la que toda certeza anterior se derrumba. No se trata aquí de esquemas conceptuales, como apunta Badawī $(1962,14)$, sino de experiencias vitales de abandono y explotación. Rābi'a se pone en pie gracias al reconocimiento y acogida de un Otro cercano que la levanta del barro. La dignidad reconocida por los otros favorece la liberación: «Te he concedido la libertad. Si quieres permanecer aquí, seguiremos juntos a tu servicio", le dice el amo ('Atțār, 1962, 144).

En su biografía, al-'Atțāar continúa relatando que, tras ejercer el oficio de tañedora de flauta, se hizo eremita y se consagró a las obras de piedad: «elle était constamment occupée aux œuvres de piété » ('Attar, 1976, 85) ${ }^{3}$. Rābía siempre mantuvo una viva relación con su Dios. Sin embargo, no faltan interpretaciones que, identificando tañedora de flauta con pecadora pública o prostituta ${ }^{4}$, defienden dos vidas contrapuestas y sucesivas para Rābi‘a, como el imaginario masculino hizo con María Magdalena, de la que en ningún momento se lee en los evangelios que fuera prostituta. Badawī presenta la conversión de Rābía como el cambio radical de una vida de desenfreno, sensualidad y pecado a una vida de entrega a Dios; y entiende, además, su amor a la divinidad como proyección o sublimación de una experiencia amorosa previa $(1962,17)$. El filósofo egipcio incluso conjetura que fue Rābaḥ al-Qaysī quien observó su inclinación a la vida de castidad y la impulsó a abandonar su anterior vida $(1962,18)$.

Los relatos de la peregrinación a la Kaaba, con los que continúa la biografía del poeta persa al-Ațtāar, tras el relato de su liberación ('Attar, 1976, 85-88), constituyen, a mi parecer, una alegoría de la relación dialógica entre Rābi'a y el Señor de la Kaaba. La Piedra Negra o Casa es símbolo de Quien ella busca, pero, insatisfecha, ya no querrá la Kaaba, sino al Señor de la Kaaba ('Attar, 1976, 85). No podemos apreciar el valor

[2] «Cuando creció y murieron su madre y su padre, acaeció una hambruna en Basora, y se separaron sus hermanas. Cuando Rābía salió y andaba errante, la vio un inicuo y la vendió por seis dírhams. Quien la compró le impuso pesadas tareas. Cierto día vino un hombre forastero, y ella huyó y se marchó por su camino. Después cayó rostro en tierra y dijo: “Mi Señor!, soy forastera, huérfana y estoy prisionera pues me he convertido en una esclava, pero mi preocupación mayor es saber si Tú estás satisfecho conmigo o no lo estás". Y oyó una voz que le decía "No estés triste porque en el día del Juicio, quienes están próximos en el cielo te verán y te envidiaran por el lugar que ocuparás en él" " ('Aț̣ār, 1962, 144. T. de la A. de la versión árabe de Badawī).

[3] Los textos citados en francés ('Attar, 1976 ) y español (Nurbakhsh, 1999) se reproducen literalmente con sus propios signos de puntuación. Todos los textos árabes citados son traducidos por la autora.

[4] «'Suonatrice di flauto’ equivale a pubblica peccatrice» (Valdré, 2001, 92). 
de esta biografía persa — que nada tiene de ingenua-, si no es penetrando en el rico sentido del relato, siempre abierto a nuevas lecturas y nuevos descubrimientos. En cierto modo, esta alegoría evoca la alegoría del huerto (jardín místico) construida por Teresa de Jesús, en el Libro de la Vida, donde la escritora compara el encuentro con Dios (grados de oración) con los cuatro modos de regar el vergel (la interioridad, la propia persona): desde el esfuerzo ímprobo del hortelano (orante) hasta que el Señor hace todo el trabajo, haciéndose presente para que se produzca la unión.

En los comienzos de la búsqueda, la orante Rābi'a al-'Adawiyya se pone en camino rodando sobre sus riñones:

Cheïkh Ali Farmezi raconte que, lorsque arriva lépoque du pèlerinage, Rābía, prenant la direction du désert, se roula sur les reins et arriva ainsi en sept années à la Kéabeh. Lorsqu'elle y fut parvenue, elle entendit une voix qui lui disait : «Que désires-tu Rābía ? [»] [...] - Mon Dieu, répondit-elle [...]. Je ne demande qu'une parcelle de pauvreté spirituelle. » [...] Elle n’avait pas achevé ces paroles que, soudain, ses menstrues lui vinrent, et elle se trouva en état d'impureté. En même temps une voix lui cria : « Le premier degré auquel parviennent les amoureux est exactement figuré par un homme qui, après sêtre roulé sur ses reins pendant sept ans, arriverait pour visiter un mur de briques et qui, en approchant de ce mur, se barrerait à lui même la route para suite d'un empêchement né de sa propre personne ». Rābía, découragée, dit : « Mon Dieu, tu ne me laisses pas masseoir dans ma propre maison et tu ne veux pas madmettre dans la tienne. Ou laisse-moi m'installer tranquillement chez moi, à Basra, ou permets-moi d'entrer dans la Kéabeh, qui est ta demeure [...] ('Attar, 1976, 86-87) .

Este es el último viaje que relata al-'Atțār, tomando como fuente a Abū 'Alī al-Farmidīī ${ }^{6}$. Probablemente, el biógrafo yuxtapone las diferentes fuentes que tratan de la peregrinación sin pretensión cronológica. Sin embargo, en mi opinión, este viaje sería el primero que habría que atribuir a Rābi‘a, pues en este nivel de exterioridad y apariencias se situaría la mayoría de los ascetas de su tiempo. Ella pretende aquí acceder al Otro contando con su solo esfuerzo. Rābi'a sufre desconcierto y desazón, y la

[5] «El maestro Abū 'Alī al-Farmidịi cuenta que, cuando llegó la época de la peregrinación, Rābía, tomando el camino del desierto, rodó sobre sus riñones y tardó siete años en llegar a la Kaaba. Cuando llegó, oyó una voz que le decía: “¿Qué deseas Rābiáa?”] [...]. "Dios mío — respondió- [...]. No pido más que una porción de pobreza espiritual". [...] Apenas había terminado de hablar, cuando le vino la menstruación y se encontró en estado de impureza ritual. Al mismo tiempo, una voz exclamó: "El primer grado al que llegan los amantes está figurado exactamente por un hombre que, después de haber rodado sobre sus riñones durante siete años, llegara a visitar un muro de ladrillos y, aproximándose a ese muro, se impidiera a sí mismo el camino por un impedimento nacido de su propia persona". Rābía, desanimada, dijo: "Dios mío, no me dejas asentarme en mi propia casa y no quieres admitirme en la tuya. O déjame instalarme tranquilamente en mi casa, en Basora, o permíteme entrar en la Kaaba que es tu morada [...]"” ('Attar, 1976, 86-87. T. de la A.).

[6] Maestro sufí (m. 1084-85). Fue discípulo de Abū l-Qāsim al-Qušayrī (Badawī 1962, 36). Al-Gazālī (m. 111) fue discípulo de al-Fārmidīi en Nishapur (Böwering, 2012). 
invade la oscuridad. Esta oscuridad sí se asemejaría a la experimentada por Pablo de Tarso camino de Damasco (Hechos de los Apóstoles 9, 1-18). El Otro se comunica y se manifiesta de modo sorprendente. El que se pone en camino tiene que despojarse de lo aprendido para llegar a Él. Rābía reconoce sus propios límites, simbolizados en la menstruación, y crece en humildad y pobreza espiritual: " Je te cherchais sans avoir courbé la tête devant la Ke'abeh ; maintenant laisse-moi m'en aller, car je ne suis pas digne d'entrer dans ta maison" ('Attar, 1976, 87) 7 .

En el segundo grado - el primer relato de peregrinación que refiere al-'Atțār-, el Señor interviene sanándole el asno, el medio de transporte. Podríamos encontrar un paralelismo en el segundo modo de regar el huerto, en el que comienza a haber «intervención sobrenatural» — afirma Teresa (Libro de la Vida 17, 1)—. Aquí, Rābi‘a se da cuenta de que no puede llegar hasta el Otro sin su ayuda. La pide, y la recibe:

Un jour elle se rendait à la Kéabeh, ayant en sa possession un âne quelle avait chargé de ses effets. Cet âne étant mort, les gens de la caravane dirent : " nous allons charger ton bagage sur nos bêtes. - Mais dit Rābía [...] c'est dans le Seigneur très haut que je mets ma confiance; partez donc. » Une fois la caravane partie, s'adressant au Seigneur : "Mon Dieu, dit-elle, est-ce ainsi que les rois en usent avec les serviteurs faibles et impuissants ? [...] » À peine avait-elle prononcé ces paroles que l'âne se releva plein de vie ('Attar, $1976,85)^{8}$.

En el tercer viaje, Él lo hace casi todo, pues es la Kaaba la que viene a ella. El bastón en el que se apoya podría indicar una edad madura. El Otro se acerca, pero aún no se produce la visión, el encuentro que anhela:

Ibrahim Edhem mit quatorze années à se rendre à la Kéabeh, car à chaque pas il faisait une prière de deux rik'at. Il disait : « Les autres marchent sur cette route avec leurs pieds; moi, j’y marche avec ma tête. » [...] lorsqu'il fut près de la Ke'abeh, il ne la vit pas à sa place. [...] Puis il aperçut Rābía qui s’avançait appuyée sur un bâton. " Ô Rābía ! lui dit-il, quelle œuvre est la tienne et quel bruit tu fais dans le monde ! car tous disent : La

[7] «Yo te buscaba sin haber inclinado la cabeza ante la Kaaba; ahora, déjame partir, pues no soy digna de entrar en tu Casa». T. de la A.

[8] «Rābía solo tenía un burro para llevar su equipaje cuando entró en el desierto en su peregrinación a La Meca. En mitad del desierto murió el burro. Sus compañeros de viaje se ofrecieron a llevar sus bultos, pero contestó: "Marchaos. No inicié mi peregrinación depositando en vosotros mi confianza." La caravana siguió su camino, abandonándola. "Dios mío, ¿es este el modo en que los Soberanos se comportan con las mujeres desamparadas?”, exclamó Rābía. “¡Me invitaste a tu morada, y en el camino muere mi burro, dejándome tirada en el desierto abrasador!” Al instante su burro recobró la vida y se levantó. Volvió a cargarlo con su equipaje y prosiguió» (Nurbakhsh, 1999, 29). 
Kéabeh est allée au-devant de Rābía. » [...] — Ô Ibrahim ! reprit Rābía, tu es venu avec la prière et moi avec l'indigence " ('Attar, 1976, 85-86) ${ }^{9}$.

Rābi‘a contrapone ahora el esfuerzo físico y la práctica ritual externa (șalāt) —considerados como méritos ostensibles que garantizarían por sí mismos el acceso a la divinidad - a la pobreza espiritual (faqr) y la humildad como únicas ofrendas. En este episodio, tan subversivo como el siguiente, Rābi‘a transmite la misma enseñanza que Jesús de Nazaret con su parábola del publicano y el fariseo, en la que el fariseo, ufano de sus prácticas religiosas sobreañadidas, creía tener a Dios de su lado (Lucas 18, 9-14).

Para concluir con esta propuesta del progreso de Rābi'a en su relación con el Otro, ubicamos aquí los dos viajes restantes. Al-'Ațtār los sitúa inmediatamente antes del encuentro con el asceta Ibrāhīm ibn Adham. El Otro protagonista se acerca, pero a ella no le bastan ya las mediaciones, su sed es inmensa. Rābi'a solo aspira a contemplarlo (el cuarto grado de oración en Teresa: Libro de la Vida 18):

On raconte qu'un jour, comme elle se rendait à la Keabeh, elle restait seule dans le désert. « Mon Dieu, dit elle, mon cœur est en proie à la perplexité au milieu de cette solitude. Je suis une brique et la Kéabeh est une pierre. Ce qu'il me faut, c'est la contemplation de ta face. » [...] On raconte qu’une autre fois, comme Rābía se rendait à la Kéabeh, elle la vit venir en plein désert au-devant d’elle. "Ce qu'il me faut à moi, dit Rābiáa, c’est le maitre de la Kéabeh et non la Ke'abeh ; quai-je à faire d’elle? » Et elle ne daigna pas la regarder ('Attar, 1976, 85) ${ }^{10}$.

El relato de las peregrinaciones tiene estructura de relación dialogal entre los dos protagonistas, Rābi'a y Allāh. Desde esa perspectiva dia-

[9] «Dicen que Ibrāhīm ibn Adham (m. 782) tardó catorce años en cruzar el desierto hasta llegar a la Kaaba. "Otros van andando a la Meca," observó, "mientras yo voy caminando con los ojos." Su manera era hacer dos genuflexiones rituales por cada paso que daba. Al llegar a La Meca, sin embargo, la Kaaba había desaparecido. “¿Qué ha ocurrido?”, dijo frotándose los ojos, “¿se me habrá nublado la vista?” “Tu vista está bien," le contestó una voz misteriosa. "Solo que la Kaaba ha salido a recibir a una dama en su viaje hasta aquí.” “QQuién puede ser?”, gritó lleno de celos. Entonces vio a Rābía caminando apoyándose en su bastón. La Kaaba regresó a su lugar. “¡Oh Rābía!, ¿ ¿por qué este tumulto y conmoción que has creado en el mundo?” preguntó Ibrāhīm. Rābía replicó: “Tú eres la causa real de la conmoción del mundo por haber dedicado catorce años a cruzar el desierto en busca del santuario de Dios". "Por supuesto," alegó, "durante catorce años estuve abstraído con la oración ritual en mi viaje." "Viajaste con la oración ritual," respondió Rābiaa, "mientras yo seguía mi camino por medio de la súplica [personal y la indigencia]”»( Nurbakhsh, 1999, 29-30).

[10] «Se cuenta que un día, cuando se dirigía a la Kaaba, permaneció sola en el desierto: “Dios mío! exclamó-, mi corazón es presa de la perplejidad en medio de esta soledad. Yo no soy más que barro y la Kaaba una piedra. Lo que yo necesito es la contemplación de tu rostro". [...] Se cuenta que, otra vez, cuando Rābía se dirigía a la Kaaba, la vio venir en pleno desierto delante de ella. "Lo que yo necesito — dijo Rābi'aes el Señor de la Kaaba y no la Kaaba; qué voy a hacer yo con ella?". Y desdeñó mirarla» ('Attar, 1976, 85. T. de la A). 
logal, podemos ver las semejanzas con la alegoría del huerto, utilizada por Teresa de Jesús para ilustrar el progreso en el trato de amistad con Dios; si bien en la alegoría persa se produce un múltiple juego de sentidos con el símbolo de la Kaaba: de una parte, es símbolo de Dios que se acerca a ella, como el agua de Teresa; de otra, es constructo religioso que se interpone.

La alusión al retiro de Rābía en su casa, enmarca el relato de las peregrinaciones: sale de su casa y vuelve a ella renovada. Rābi'a atraviesa el desierto, la perplejidad y la oscuridad, gracias a lo cual, depura la religión de toda cosificación para vivirla y enseñarla en clave de relación interpersonal. Ella aspira a un encuentro personal, afectivo; y no tanto al conocimiento de la $\operatorname{Verdad}^{11}$, como a la contemplación de la Belleza. El conocimiento del Otro lo adquiere en la experiencia amorosa. Una vez asemejados los amantes por el amor, se alcanza la contemplación. El alto grado de conocimiento al que llega Rābi'a se deriva de la unión alcanzada. $\mathrm{Y}$ ese conocimiento amoroso, reconocido en su tiempo, ha sido admirado por la posteridad. Mediante un proceso de interiorización, Rābi‘a hace de la religión-institución una religión del corazón, una experiencia que brota de la interioridad, para iluminar y transformar el mundo. Rābi‘a no vive recluida, sino apartada en medio del mundo; está en el mundo sin ser del mundo, como diría Jesús de Nazaret (Juan 17, 6. 15-16). El camino hacia el Otro, la busca de la intimidad con el amado, requiere distanciamiento y relativización de lo transitorio y caduco. La Otredad se descubre en el recogimiento.

\section{Crítica religiosa y Kaaba}

Desde la conciencia de una íntima presencia del Otro, desde la experiencia amorosa y liberadora del Amado, las rupturas con formalismos, tradiciones y materialismo son inevitables. Gracias a un desarrollo espiritual dialógico, esta mujer del siglo VIII, Rābi‘a al-'Adawiyya, goza de prestigio y libertad en el seno de la comunidad islámica. Ella inaugura la morada del amor divino en el ámbito del sufismo.

En relación con su crítica del formalismo y la cosificación, se citan la sentencias sobre la Kaaba que comenta Ibn Taymiyya: «Es un ídolo adorado en la Tierra»; "Dios no ha estado allí y nunca la ha dejado» (1962, $131 ; 132)$.

[11] Algunos autores y corrientes sufíes mantienen una actitud profundamente intelectual. Al-Haqq designa la Verdad o Realidad, la realidad esencial, la Divinidad. Un motivo de aspiración a Dios es el conocimiento. Pero Dios también se ha mostrado como objeto de deseo en las religiones monoteístas. 
Badawī considera que una frase que supondría la defensa de un Monismo existencial o Panteísmo podría no ser de Rābi‘a (Badawī, 1962, 81). No obstante, la afirmación de que no ha estado allí (encerrado, limitado) y de que nunca la ha dejado (porque está en todas partes) es compatible con la enseñanza de Jesús de Nazaret, a quien no se le podría acusar de predicar el monismo existencial: se trata de adorar en espíritu y verdad en cualquier lugar, pero, sobre todo, en el interior de uno mismo ${ }^{12}$. Respecto a considerar "La Casa" un ídolo sobre la tierra, el Corán ya advierte de que las gentes adoran la piedra sin Dios (Corán 106, 3-4). La sentencia atribuida a Rābi'a comprende también una crítica de la deriva de la religión hacia la idolatría o adoración de imágenes o lugares.

Rābi‘a afirma que no quiere la Kaaba, sino al Señor de la Kaaba ('Attar, 1976, 85). Esta idea reviste, a juicio de Badawī, el mayor grado de importancia — de ser cierto el relato que transmite al-'Atțār—: «pues es la misma idea que desempeñó un grave (jațīr) papel en la doctrina (madhab) de al- Hallāây, ya que se contó entre las causas de su condena y ejecución» (Badawī, 1962, 39).

Rābi‘a defiende, por tanto, en los inicios del islam la idea innovadora que Jesús de Nazaret enseñó a la mujer samaritana que le daba de beber: el culto debe hacerse en espíritu y verdad ${ }^{13}$. Rābi'a será la primera persona que introduzca esta innovación en el sufismo. Ella aporta una nueva concepción de la Religión, depura la Religión de lo que es accidental, anecdótico o incluso distrae de la relación esencial. Rābi‘a al-'Adawiyya, mujer de luz (iluminada, alumbrada, ilustrada), es la maestra que ilumina el camino sufí, la corriente mística del islam, como faro y guía por la senda del amor.

\section{Referencias bibliográficas}

'Atțār al-: "Rābi'a al-'Adawiyya". En Tadkirat al-awliyā', en Badawī, 'A. al-R.: Šahìdat al- ‘š́q al-ilāhī. Rābi'a al-'Adawiyya. El Cairo: Maktabat al-nahḍa al-mișriyya, 1962, pp. 142-160.

'Attar, F.: Le mémorial de Saints. París: Seuil, 1976.

[12] «Cuando tú vayas a orar, entra en tu habitación, cierra la puerta y reza a tu Padre a escondidas. Y tu Padre, que ve en lo escondido, te lo pagará» (Mateo 6, 6).

[13] «Pero llega la hora, ya ha llegado, en que los que dan culto auténtico darán culto al Padre en espíritu y de verdad. Tal es el culto que busca el Padre. Dios es Espíritu y los que le dan culto deben hacerlo en espíritu y de verdad» (Juan 4, 23-24). 
Badawī, 'A. al-R.: Šahīdat al- 'išq al-ilāhī [Testigo del deseo divino]. Rābi'a al'Adawiyya. 2. ${ }^{\text {a }}$ ed. El Cairo: Maktabat al-nahḍa al-mișriyya, 1962.

Bahā' al-Dīn al- 'Āmilī, M.: Kaškūl [Tazón del mendigo], en Badawī, 'A. al-R.: Šahīdat al-'išq al-ilāhñ. Rābi'a al- 'Adawiyya. El Cairo: Maktabat al-nahḍa al-mișriyya, 1962, pp 164-165.

Bajtín, M. M.: Estética de la creación verbal. México: Siglo Veintiuno Ediciones, 2009.

Biblia de Jerusalén. Bilbao: Desclée de Brouwer, 1990.

Böwering G. [en línea]: "Gazālī, Abū Ḥamed Moḥammad", en Encyclopaedia Iranica (2012), http://www.iranicaonline.org/articles/gazali-i-biography [Consultado: 17/01/2016].

Ibn Taymiyya: Maŷmū'at al-rasā'il wa-l-masā’il [Compilación de tratados y cuestiones], en Badawī, 'A. al-R.: Šahīdat al-'išq al-ilāhī. Rābi'a al-'Adawiyya. El Cairo: Maktabat al-nahụa al-mișriyya, 1962, pp. 131-132.

Nurbakhsh, J.: Mujeres Sufies. Madrid: Ediciones Nur, 1999.

Sviri, S.: "Sufism: reconsidering terms, definitions and processes in the formative period of islamic mysticism" en Gobillot, G. y Thibon J.-J. (dirs.): Les maîtres soufis et leurs disciples. III ${ }^{e}-V^{e}$ siècles de l'hégire (IX'e-XI's.). Enseignement, formation et transmission. Damasco/Beirut: Institut français du Proche Orient, 2012, pp. 17-34.

Teresa de Jesús, Santa: Libro de la Vida. Ed. D. Chicharro. Madrid: Cátedra, 1993.

Valdrè, C. (ed.): I detti de Rābi‘a. Milano: Adelphi Edizioni, 2001. 
